\title{
Synthesis and Characterization of Chitosan Biguanidine Hydrochloride under Microwave Irradiation
}

\author{
By Xue ZHAO, ${ }^{1}$ JIN-xin HE, ${ }^{1,2, *}$ and Yi-zhen $Z_{H A N}^{3}$
}

Chitosan biguanidine hydrochloride was synthesized by reacting chitosan with dicyandiamide under microwave irradiation. The influence of reaction temperature, reaction solvent and microwave heating time was studied, and optimal conditions were identified. The representative microwave synthesized chitosan biguanidine hydrochloride was characterized by Fourier transform infrared spectroscopy, scanning electron microscopy and X-ray diffraction measurement, taking chitosan as a reference. The solubility $\mathrm{pH}$ for the chitosan biguanidine hydrochloride with different substitution degrees was monitored. The antimicrobial activities of chitosan biguanidine hydrochloride were measured by means of the minimal inhibition concentration (MIC). In vitro antimicrobial activity of guanidinylated chitosans with different substitution degrees were evaluated against staphylococcus aureus, bacillus subtilis, escherichia coli and pseudomonas aeruginosa. The results show that the microwave irradiation method can increase the reaction rate by twelve times over the conventional method. Chitosan biguanidine hydrochloride are effective of bacteriostasis, compared with chitosan, guanidinylated chitosan had much better antibacterial activity. The antibacterial activity of chitosan biguanidine hydrochloride derivative enhanced with increasing substitution degrees of guanidinylated chitosan.

KEY WORDS: Chitosan Biguanidine Hydrochloride / Synthesis / Microwave Irradiation / Antibacterial Activity /

Marine polysaccharide drugs have attracted much attention. Chitosan, one of the most important marine polysaccharides, has many peculiar biological activities such as immunity, norcholesterol, and antibacterial, and thus has prospective application in the fields of medicine, textile and biotechnology. Some antibacterial activities have been described with chitosan and modified chitosan derivatives. ${ }^{1-5}$ However, chitosan shows its biological activity only in acidic medium because of its poor solubility above $\mathrm{pH}$ 6.5. Thus, water soluble chitosan derivatives which are soluble in both acid and basic physiologic circumstances might be good candidates for a polycationic biocide. $^{6-11}$

Chitosan possesses primary amino groups in its structure and the number of these amino groups is related to its antimicrobial activity. The introduction of asparagine to chitosan oligosaccharide significantly improved the bactericidal activity and minimum inhibitory concentration; this probably indicates that the higher the number of amino groups, the higher the antimicrobial activity. ${ }^{12}$ Guanidinium salts have attracted increasing interest in recent years, the guanidine derivatives with antimicrobial and antifungal activity have been investigated as medical and crop protection agents and antiseptics for industry products, food and other goods for daily use. ${ }^{13-18}$ Few studies have investigated the feasibility of guanidinylated chitosan. ${ }^{19}$ Therefore, possibility of guanidinylated chitosan with multi-amino groups seemed attractive.

Microwave irradiation has received increasing interest in organic synthesis due to the remarkable enhancement of the rates of some organic reactions over conventional reaction. Microwave energy can directly and uniformly be absorbed throughout the entire volume of an object, causing it to heat up evenly and rapidly. Recently, ${ }^{20,21}$ microwave irradiation has been extended for use in the chemical modification of polysaccharides such as starch and chitosan. ${ }^{22-26}$ In this paper, we report a novel guanidinylated chitosan derivative: chitosan biguanidine hydrochloride (Figure 1), which was prepared by chitiosan with dicyandiamide under microwave irradiation, expecting to improve its water solubility and antibacterial activity futher.

\section{EXPERIMENTAL}

\section{Materials and Equipments}

Chitosan (molecular weight $800 \mathrm{KDa}$; the degree of deacetylation $96.0 \%$ ) and dicyandiamide (CP) were supplied by Guayao chemical reagent Co. Ltd (Shanghai, China). Beef extract, agar and peptone were supplied by Yijia chemical reagent Co. Ltd (Shanghai, China). All other reagents are analytical grade provided by Beihong Yijia chemical reagent Co. Ltd (Tianjin, China). A Calanz microwave oven (WP700L17) was supplied by Shunde Galanz electric appliances Co. Ltd (Shanghai, China).

\section{Modification of Microwave Oven}

A diagram of the microwave oven used in these studies in shown in Figure 2. Three holes were drilled into the oven to

\footnotetext{
${ }^{1}$ College of Chemistry, Chemical Engineering and biotechnology, Donghua University, 2999 North Renmin Road Shanghai Songjiang 201620, P. R. China

${ }^{2}$ Key Lab of Textile Science \& Technology, Ministry of Education, China

${ }^{3}$ Saintyear Holding Group Company, Hangzhou 311221, China

*To whom correspondence should be addressed (Tel: +086 21 67792602, Fax: 0086-21-67792608, E-mail: jxhe@dhu.edu.cn (HE JIN-xin)).
} 


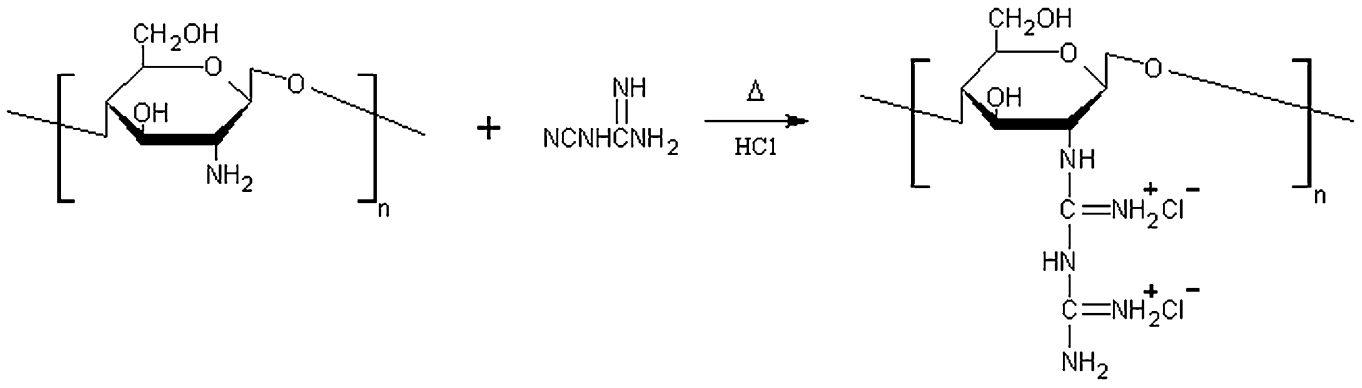

Figure 1. The synthesis of chitosan biguanidine hydrochloride.

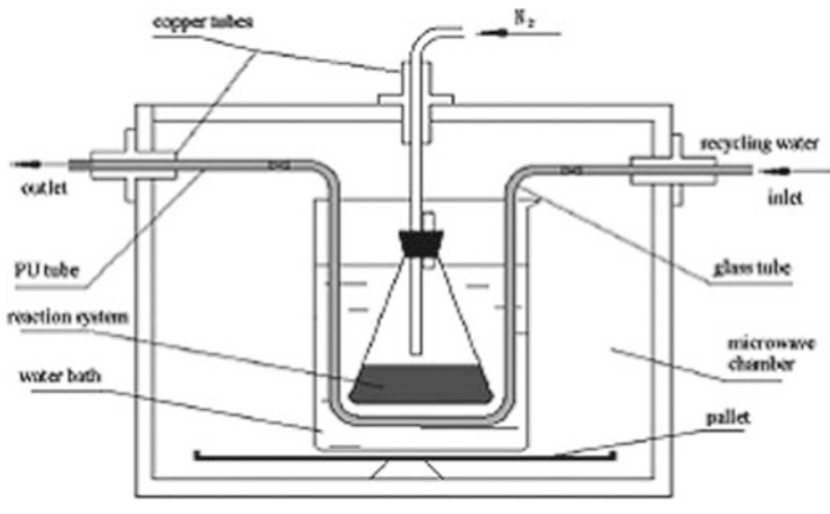

Figure 2. Schematic of modified microwave oven.

provide the inlet and outlet for recycling thermostat water, and the inlet for nitrogen gas. The holes were jacketed with copper tubing to avoid microwave leakage. The recycling thermostat water was provided by a thermostated water bath. Using this apparatus, the highest reaction temperature was $100^{\circ} \mathrm{C}$ and temperature variation could be controlled under low or middle microwave power.

\section{Preparation of Chitosan Biguanidine Hydrochloride}

Chitosan $(2.0 \mathrm{~g}, 2 \% \mathrm{w} / \mathrm{v})$ dissolved in $0.15 \mathrm{~mol} / \mathrm{L}$ hydrochloric acid and the desired amount of dicyandiamide (corresponding to a molar ratio of 1:1 compared with chitosan residue) were irradiated in a microwave oven in an Erlenmeyer flask and then it was cooled to room temperature. The mixture was washed thoroughly with ethanol, then dried under vacuum to constant weight to give product chitosan biguanidine hydrochloride. Reaction was repeated with different reaction solvent, reaction temperature and microwave heating time.

Different substitution degrees guanidinylated chitosan prepared from chitosan were synthesized using different amounts of dicyandiamide (corresponding to a molar ration of 1:1( $\left(\mathrm{CGH}_{1}\right) \quad 1: 2\left(\mathrm{CGH}_{2}\right), \quad 1: 3\left(\mathrm{CGH}_{3}\right), \quad 1: 4\left(\mathrm{CGH}_{4}\right), \quad 1: 5\left(\mathrm{CGH}_{5}\right)$ compared with chitosan residue) using the same method as above, reaction temperature, $90^{\circ} \mathrm{C}$; reaction solvent, $0.15 \mathrm{~mol} /$ $\mathrm{LHCl}$; microwave heating time, $15 \mathrm{~min}$. $\mathrm{IR}\left(\mathrm{KBr}, \mathrm{cm}^{-1}\right)$ : $\gamma 3377(\mathrm{OH}), 2940(\mathrm{C}-\mathrm{H}), 1154$ and 1094(-C-O- in the ether groups).

\section{Characterization}

Infra red (IR) spectra were recorded in powder form in $\mathrm{KBr}$ discs in the range of $4000-500 \mathrm{~cm}^{-1}$ on a Nicolet NEXUS-670 Infra red spectrophotometer. X-Ray diffraction (XRD) was carried out on Rigaku D/Max-2550 PC X-ray powder diffractometer. SEM analysis was done on JEOL JSM5600LV machine. The substitution degree of guanidinium derivatives (DS) was calculated according to the $\mathrm{C} / \mathrm{N}$ wt $\%$ from the elemental analysis. $\mathrm{C} / \mathrm{N}=(72+24 \times 0.04+$ $24 \mathrm{DS}) /(14+56 \mathrm{DS})$. The elemental analysis $(\mathrm{C}, \mathrm{N}, \mathrm{H})$ of samples was performed on an Elmentar Vario EL III Elemental Analyzer. ${ }^{13} \mathrm{C}$ NMR spectra were recorded on a Bruker Avance $400 \mathrm{NMR}$ spectrophotometer. Samples were dissolved in $\mathrm{HCl} /$ $\mathrm{D}_{2} \mathrm{O}$. Molecular weights $\left(M_{\mathrm{w}}\right)$ of sample was measured by gel permeation chromatography (GPC) on connected columns (TSK G5000-PW or TSK G3000-PW), using an RI 150 refractive index detector using $0.2 \mathrm{M} \mathrm{CH} \mathrm{CH}_{3} \mathrm{COOH} / 0.1 \mathrm{M}$ $\mathrm{CH}_{3} \mathrm{COONa}$ as eluent at a flow rate of $1.0 \mathrm{~mL} / \mathrm{min}$. The standards used to calibrate the column were pullulan. The solubility $\mathrm{pH}$ for the chitosan biguanidine hydrochloride with different substitution degrees was evaluated from PHSJ-4A pH meter.

\section{Measurement of Minimal Inhibition Concentration}

The cultures, obtained by growing the bacteria overnight at $37{ }^{\circ} \mathrm{C}$ in nutrient broth (peptone $0.5 \%$, beef extract $0.3 \%$, pH $7.0 \pm 0.2\left(25^{\circ} \mathrm{C}\right)$ ), were diluted with sterile normal Saline $(0.9 \%)$ solution, each of the culture suspensions containing $c a$. 106-107 CFU/mL, which was used for the antibacterial test.

Chitosan biguanidine hydrochloride and chitosan $(0.1 \mathrm{~g}$, $0.075 \mathrm{~g}, 0.05 \mathrm{~g}, 0.025 \mathrm{~g}, 0.01 \mathrm{~g})$ was dissolved in $1 \% \mathrm{v} / \mathrm{v}$ acetic acid $(10 \mathrm{~mL}$ ), nutrient agar (peptone $0.5 \%$, beef extract $0.3 \%$, agar $1.5 \%$, pH $\left.6.8 \pm 0.2\left(25^{\circ} \mathrm{C}\right)\right) 90 \mathrm{~mL}$ were mixed, $\mathrm{pH}$ values of Chitosan biguanidine hydrochloride and chitosan sample solutions with different concentrations $0.1 \%, 0.075 \%$, $0.05 \%, 0.025 \%, 0.01 \%$ were adjusted by addition of $1.0 \mathrm{~mol} / \mathrm{L}$ $\mathrm{NaOH}$ to 6.0. All solutions were autoclaved at $121^{\circ} \mathrm{C}$ for $15 \mathrm{~min}$.

Minimum inhibitory concentration (MIC) determination: the above sample solutions $(15 \mathrm{~mL})$ were heated to $45^{\circ} \mathrm{C}$ and poured into autoclaved petri-dishes, cooled, one loopful of microorganism suspension was spread on cooled nutrient agar, then incubated at $37^{\circ} \mathrm{C}$. The MIC was defined as the lowest concentration of the tested sample at which the microorganism 
Table I. Investigated variables and their levels

\begin{tabular}{cccc}
\hline $\begin{array}{c}\text { Levels of each } \\
\text { variable }\end{array}$ & $\begin{array}{c}\text { A: reaction } \\
\text { temperature } \\
\left({ }^{\circ} \mathrm{C}\right)\end{array}$ & $\begin{array}{c}\text { B: reaction } \\
\text { solvent }\end{array}$ & $\begin{array}{c}\text { C: microwave heating } \\
\text { time } \\
(\mathrm{min})\end{array}$ \\
\hline 1 & 80 & Water & 10 \\
2 & 90 & $0.15 \mathrm{~mol} / \mathrm{LHCl}$ & 15 \\
\hline
\end{tabular}

Table II. Orthogonal experimental arrangement and yield test results

\begin{tabular}{|c|c|c|c|c|c|}
\hline \multicolumn{2}{|c|}{ Experiment number } & $A$ & B & $\mathrm{C}$ & Yield/\% \\
\hline \multicolumn{2}{|l|}{1} & 1 & 1 & 1 & 40.5 \\
\hline \multicolumn{2}{|l|}{2} & 1 & 2 & 2 & 74.7 \\
\hline \multicolumn{2}{|l|}{3} & 2 & 1 & 2 & 64.0 \\
\hline \multicolumn{2}{|l|}{4} & 2 & 2 & 1 & 74.1 \\
\hline \multirow[t]{2}{*}{ Average } & Level 1 & 57.600 & 52.250 & 57.300 & \\
\hline & Level 2 & 69.050 & 74.400 & 69.350 & \\
\hline \multicolumn{2}{|c|}{ Variance (average) } & 11.450 & 22.150 & 12.050 & \\
\hline
\end{tabular}

Table III. Orthogonal experimental arrangement and degree of substitution test results

\begin{tabular}{|c|c|c|c|c|c|}
\hline \multicolumn{2}{|c|}{ Experiment number } & $A$ & B & C & DS \\
\hline \multicolumn{2}{|l|}{1} & 1 & 1 & 1 & 0.31 \\
\hline \multicolumn{2}{|l|}{2} & 1 & 2 & 2 & 0.46 \\
\hline \multicolumn{2}{|l|}{3} & 2 & 1 & 2 & 0.73 \\
\hline \multicolumn{2}{|l|}{4} & 2 & 2 & 1 & 0.87 \\
\hline \multirow[t]{2}{*}{ Average } & Level 1 & 0.385 & 0.520 & 0.590 & \\
\hline & Level 2 & 0.800 & 0.665 & 0.595 & \\
\hline \multicolumn{2}{|c|}{ Variance (average) } & 0.415 & 0.145 & 0.005 & \\
\hline
\end{tabular}

colonies were not visible with naked eye within $16-38 \mathrm{~h}$. The observation time of MIC in each sample was $38 \mathrm{~h}$.

\section{RESULTS AND DISCUSSION}

\section{Optimization of Reaction Condition}

The optimum conditions for the guanidylation reaction of chitosan were investigated by independent variation of three parameters: reaction temperature (A), reaction solvent $(B)$ and microwave heating time $(\mathrm{C})$. For each parameter, the two values were investigated, as listed in Table I. Reference to the experimental design theory, the orthogonal array $\mathrm{L}_{4}\left(2^{3}\right)$ was selected to arrange the test program. Reaction yield and degree of substitution were the criterion of each synthesis. The test results are shown in Table II and Table III.

The order of influence of each variable on yield appears to be $\mathrm{B}>\mathrm{C}>\mathrm{A}$. Thus, the reaction solvent has the greatest influence on the yield. The order of influence of each variable on DS appears to be $\mathrm{A}>\mathrm{B}>\mathrm{C}$. Thus, reaction temperature has the greatest influence on the DS. The optimum level of each variable is A-2, B-2, C-2. Therefore, the optimum reaction conditions were as follows: reaction temperature, $90{ }^{\circ} \mathrm{C}$; reaction solvent, $0.15 \mathrm{~mol} / \mathrm{LHCl}$; microwave heating time, $15 \mathrm{~min}$.

Under traditional heating conditions, the reaction time needs $180 \mathrm{~min}^{24}$ This means the microwave irradiation can enhance twelve times reaction rate over the traditional heating
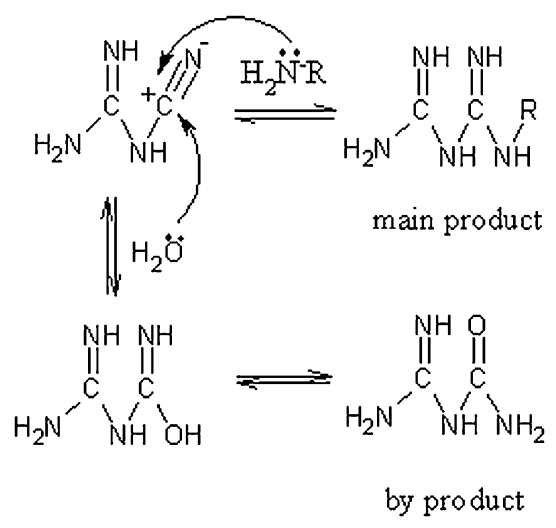

Figure 3. The nucleophilic addition reaction of chitosan, water and dicyandiamide.

method. Yield and degree of substitution increase slightly with the increase of reaction temperature and microwave heating time. On the other hand, synthesis of chitosan biguanidine hydrochloride can be readily carried out in aqueous media in the presence of a protonating agent, $\mathrm{HCl}$. It is found the side reaction of dicyandiamide hydrolyzing to guanylurea during the synthesis of chitosan biguanidine hydrochloride. The trend of the hydrolysis is significant with the increasing acidity. The hydrolysis reaction was showed in Figure 3.

\section{Characterization of Chitosan Biguanidine Hydrochloride}

Richard F. Stockel showed a general method for preparing aminosaccharide biguanides over a decade age. ${ }^{27}$ By this means, the synthesis of the chitosan biguanidine hydrochloride was achieved by a nucleophilic addition reaction of the chitosan with dicyandiamide. Fourier transform-infrared spectroscopy, ${ }^{13} \mathrm{C}$ NMR analyses, scanning electron microscopy and X-ray diffraction measurement indicated the success of the guanidylation reaction.

Figure 4 shows the IR spectra of chitosan and chitosan biguanidine hydrochloride.

The IR spectra of chitosan biguanidine hydrochloride showed new $1638 \mathrm{~cm}^{-1}$ assigned to the stretching vibration of $\mathrm{C}=\mathrm{NH}$ in guanidine group $\left[-\mathrm{HNC}(=\mathrm{NH}) \mathrm{NH}_{2}\right]$, the peak at $1601 \mathrm{~cm}^{-1}$ that had been assigned to the binding vibration of $-\mathrm{NH}_{2}$ group of chitosan had disappeared, the new stronger peak at $1435 \mathrm{~cm}^{-1}$ was assigned to the stretching vibration of $\mathrm{C}-\mathrm{N}-\mathrm{C}$ and the peak at $1330 \mathrm{~cm}^{-1}$ was assigned to the stretching vibration of $\mathrm{C}-\mathrm{N}$, it can be deduced that guanidinylation had been successful.

The ${ }^{13} \mathrm{C}$ NMR spectra of chitosan and chitosan biguanidine hydrochloride $\left(\mathrm{CGH}_{1}\right)$ in $\mathrm{HCl} / \mathrm{D}_{2} \mathrm{O}$ were showed in Figure 5.

Comparing the ${ }^{13} \mathrm{C}$ NMR spectrum of chitosan with that of chitosan biguanidine hydrochloride, the distinct signals at 158.4 and $165.8 \mathrm{ppm}$ were assigned to the carbons of biguanidine groups, and the ${ }^{13} \mathrm{C} \mathrm{NMR}$ chemical shifts for chitosan at 58.6(C2), 62.7(C6), 72.8(C3), 77.3(C5) and $79.0(\mathrm{C} 4)$ and $100.1(\mathrm{C} 1)(\mathrm{ppm})$ were detected. In contrast to chitosan, the signals of chitosan biguanidine hydrochloride 


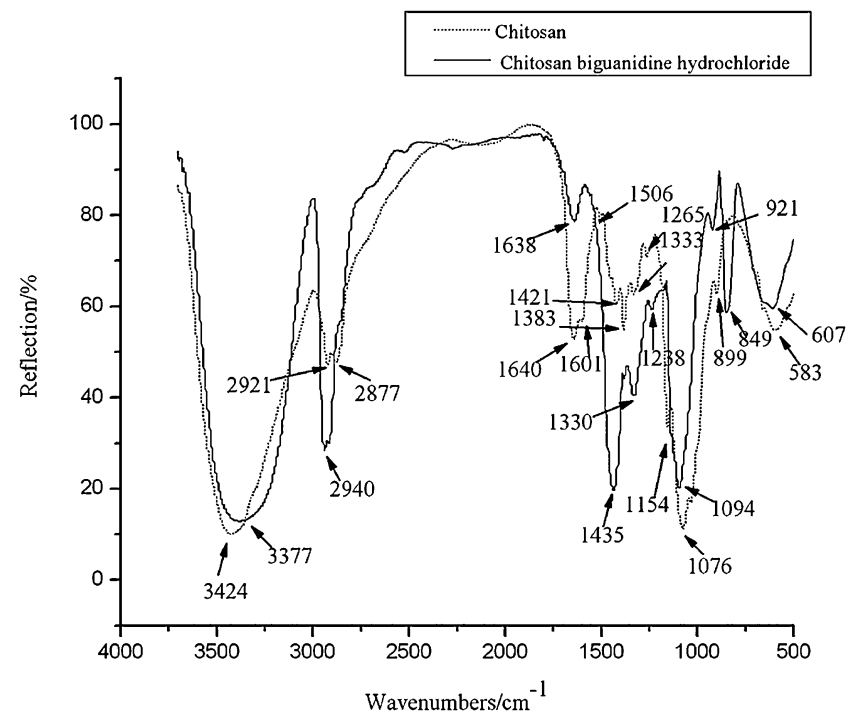

Figure 4. FT-IR spectra of chitosan and chitosan biguanidine hydrochloride.
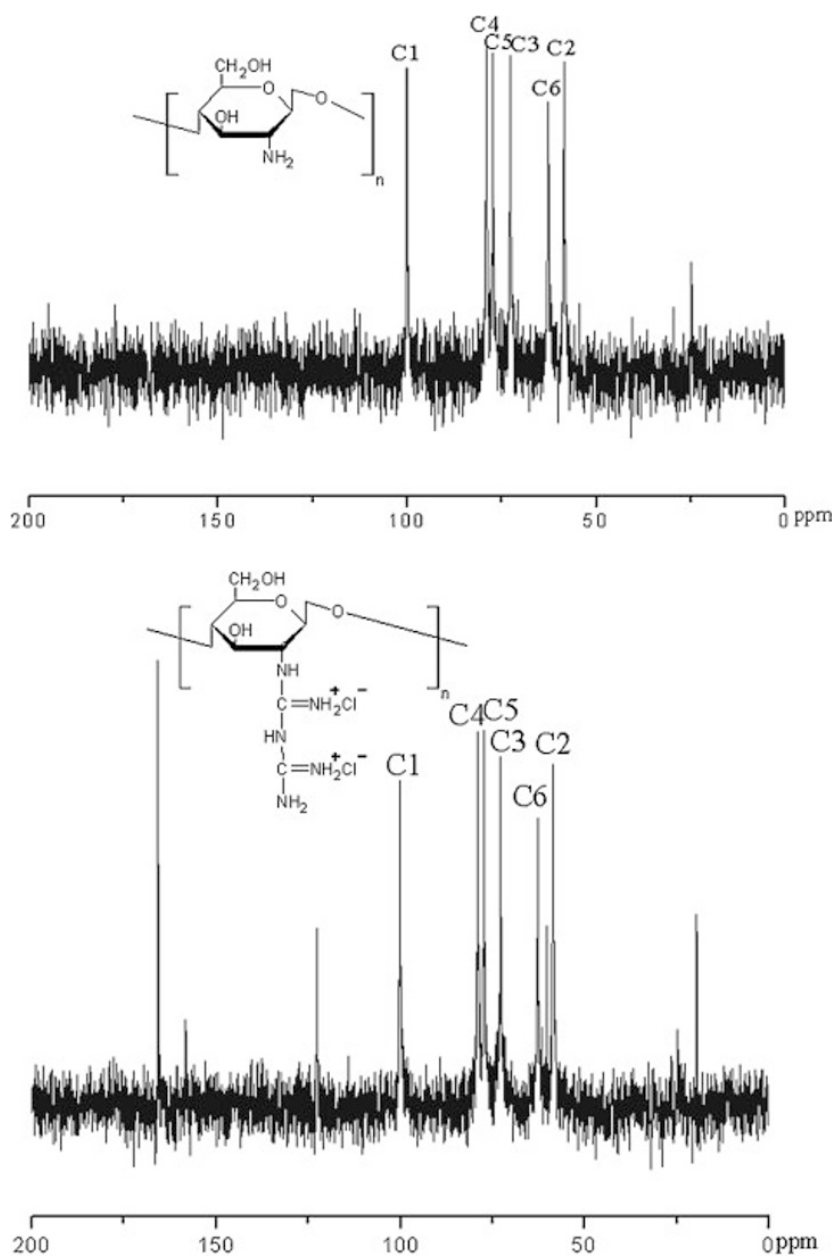

Figure 5. ${ }^{13} \mathrm{C}$ NMR spectra of chitosan and chitosan biguanidine hydrochloride.

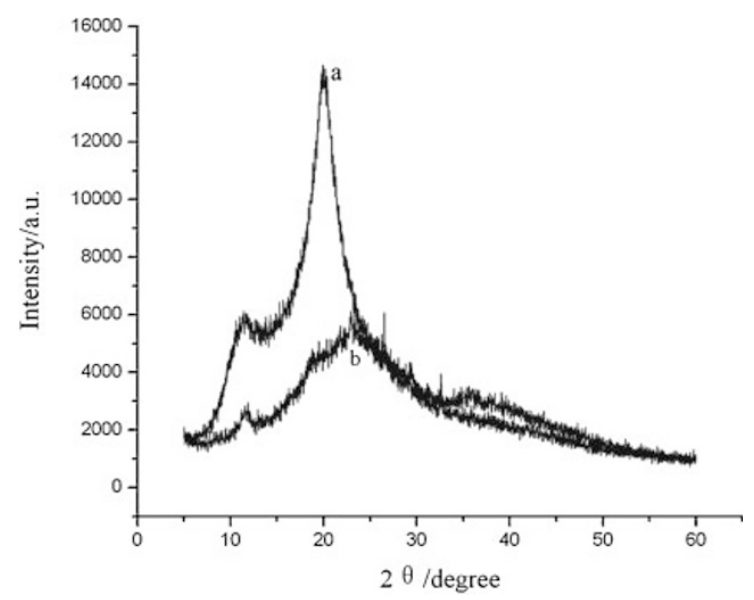

Figure 6. XRD pattern of chitosan (a) and chitosan biguanidine hydrochloride (b)

showing at 58.6(C2), 62.7(C6), 72.8(C3), 77.3(C5) and $79.0(\mathrm{C} 4)$ and $100.1(\mathrm{C} 1)(\mathrm{ppm})$ were attributed to the polysaccharide structures. The ${ }^{13} \mathrm{C}$ NMR spectra confirmed that the amino groups of chitosan being partly guanidinylated.

Guanidylation reaction of chitosan was also supported by XRD (Figure 6).

Chitosan sample shows distinct crystalline peaks at around $20^{\circ}$ compared to chitosan biguanidine hydrochloride. This is because plenty of hydroxyl and amino groups exist in the chitosan structure, which can form stronger intermolecular and intramolecular hydrogen bonds, and the structure of chitosan molecules has certain regularity, so that chitosan molecules form crystalline regions easily. However, as regards chitosan biguanidine hydrochloride, the peak at $20^{\circ} \mathrm{C}$ weakened obviously. The reason may attribute to the destruction of the intermolecular hydrogen bonds and the crystalline regions of chitosan.

The SEM pictures of chitosan and chitosan biguanidine hydrochloride $\left(\mathrm{CGH}_{1}\right)$ were shown in Figure 7.

The SEM picture of chitosan shows larger clustered structure, because there are stronger interactions between chitosan molecules. After guanidylation of chitosan, in the surface of chitosan biguanidine hydrochloride, fluffy morphology and globular shapes with some irregularities are clearly observed. It may be attributed to the polar difference between chitosan and chitosan biguanidine hydrochloride and the destruction of the intermolecular hydrogen bonds and the crystalline regions of chitosan. SEM pictures of the chitosan and the chitosan biguanidine hydrochloride also confirm guanidylation whereby a distingusished change is observed in the surface morphology after guanidylation which seems to have taken place homogeneously as a bulk and not just at the surface.

Chitosan biguanidine hydrochloride showed different solubility behavior than chitosan itself. Chitosan biguanidine hydrochloride is soluble in water at $\mathrm{pH}$ 6.0-6.5 while chitosan itself dissolves at $\mathrm{pH} 3-4$ (Figure 8). Change in the solubility confirms the success of the guanidylation reaction. 
(a)

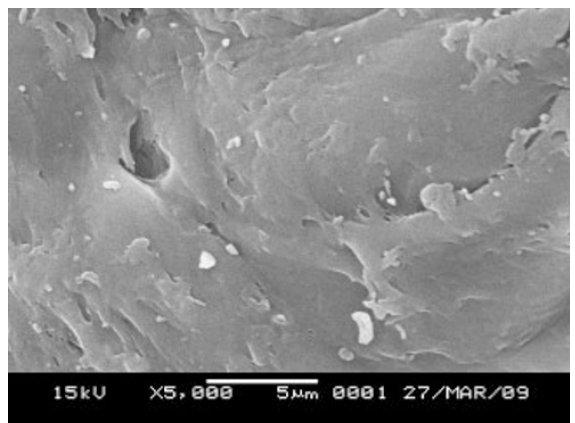

(b)

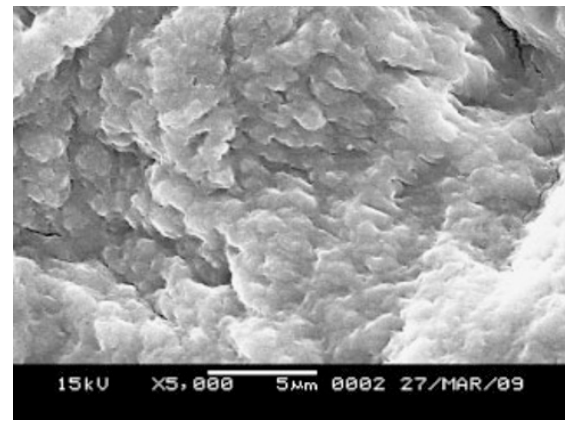

Figure 7. SEM picture of chitosan (a) and chitosan biguanidine hydrochloride (b).

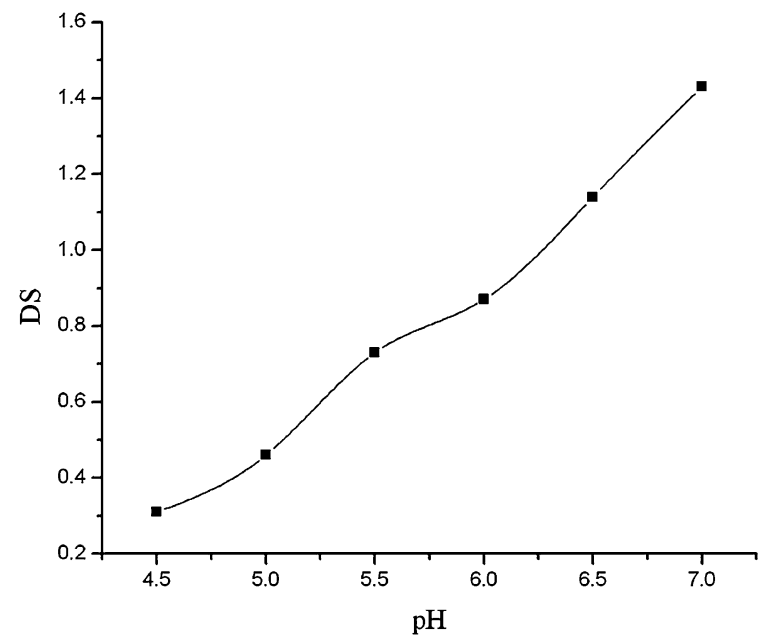

Figure 8. Solubility $\mathrm{pH}$ of chitosan biguanidine hydrochloride with increasing DS.

\section{Molecular Weight of Chitosan and Its Derivatives}

Table IV shows the $M_{\mathrm{w}}$ of chitosan and chitosan biguanidine hydrochloride measured by GPC.

The molecular weight of the chitosan and its derivatives plays an important role in the bioactivity such as antimicrobial activity. The $M_{\mathrm{w}}$ of the guanidinylated chitosans decreased with increasing microwave heating time which was attributed to degradation of the polymer backbone during modification reaction under strong acid conditions. So, after the guanidinylation reation, the molecular weights of the chitosan derivatives of guanidinium decreased.

\begin{tabular}{ccc} 
& \multicolumn{2}{c}{$\begin{array}{c}\text { Table IV. } \\
\text { and chitosan biguanidine hydrochloride }\end{array}$} \\
\hline $\begin{array}{c}\text { Chitosan } \\
\text { (before reaction) } \\
M_{\mathrm{w}}\left(\times 10^{-4}\right)\end{array}$ & $\begin{array}{c}\text { Microwave } \\
\text { heating time } \\
(\mathrm{min})\end{array}$ & $\begin{array}{c}\text { Chitosan biguanidine hydrochloride } \\
\text { (after reaction) } \\
M_{\mathrm{w}}\left(\times 10^{-4}\right)\end{array}$ \\
\hline 80 & 10 & 53.6 \\
80 & 15 & 44.8 \\
\hline
\end{tabular}

Table V. MICs of chitosan biguanidine hydrochloride with different substitution degrees in hydrochloric acid solution $(\mathrm{pH} 6.0)$

\begin{tabular}{lllllllllll}
\hline $\begin{array}{l}\text { Molar } \\
\text { ratio }\end{array}$ & \multicolumn{3}{c}{ Analysis found/\% } & \multicolumn{3}{c}{ C/N DS } & \multicolumn{4}{c}{ MICs/\% } \\
\hline \multicolumn{1}{c}{} & $\mathrm{C}$ & $\mathrm{N}$ & $\mathrm{H}$ & & \multicolumn{4}{c}{ S. aureus } & B. subtilis E. coli P. aeruginosa \\
$1: 1$ & 30.00 & 12.05 & 6.76 & 2.49 & 0.33 & 0.075 & 0.1 & 0.075 & 0.075 \\
$1: 2$ & 30.32 & 12.14 & 6.78 & 2.47 & 0.34 & 0.075 & 0.1 & 0.075 & 0.075 \\
$1: 3$ & 30.47 & 12.16 & 6.40 & 2.51 & 0.32 & 0.075 & 0.1 & 0.075 & 0.075 \\
$1: 4$ & 30.08 & 23.32 & 6.45 & 1.29 & 1.14 & 0.05 & 0.075 & 0.075 & 0.05 \\
$1: 5$ & 29.50 & 25.89 & 6.46 & 1.14 & 1.43 & 0.025 & 0.05 & 0.05 & 0.05 \\
Chitosan & 37.00 & 6.70 & 7.55 & 5.52 & 0.1 & 0.1 & 0.1 & 0.1 \\
\hline
\end{tabular}

\section{Antibacterial Activity}

The minimum inhibitory concentrations (MIC) of chitosan and chitosan biguanidine hydrochloride with different substitution degrees against two gram-positive bacteria: staphylococcus aureus and bacillus subtilis and two gram-negative bacteria: escherichia coli and pseudomonas aeruginosa are shown in Table V.

Table $\mathrm{V}$ showed that chitosan and chitosan biguanidine hydrochloride showed effective antibacterial activity against all the microorganisms tested. When chitosan had been converted into a guanidine derivative, the positive charge density of the derivative increased, which led to enhanced adsorption of polycation onto the negatively charged cell surface. Guanidinylated chitosan may be easier to associate with cell surface and show higher antibacterial activity. Reasonably, chitosan biguanidine hydrochloride showed better antibacterial activity than chitosan. The $\mathrm{C} / \mathrm{N}$ wt $\%$ of the guanidinylated chitosan is much lower than that of chitosan. With increasing molar ratio of dicyandiamide to glucosamine unit from $1: 3$ to $1: 4$, the substitution degree of guanidinium derivatives drastically increased. Furthermore, hydroxyl group in chitosan will be substituted to biguanide group because of the DS value over 1 . These situations are probably explained, in addition to acceleration by microwave irradiation, by increase of $\mathrm{pH}$ value by the addition of excess amount of dicyandiamide, which is favorable to the biguanidinylation reaction. The antibacterial activity of guanidinylated chitosan enhanced with increasing substitution degrees.

\section{CONCLUSION}

Chitosan biguanidine hydrochloride was synthesized by guanidylation reaction of chitosan under microwave irradiation. The optimum reaction conditions were determined as follows: reaction temperature, $90^{\circ} \mathrm{C}$; reaction solvent, 0.15 $\mathrm{mol} / \mathrm{LHCl}$; microwave heating time, $15 \mathrm{~min}$. Chitosan and 
chitosan biguanidine hydrochloride were characterized by means of FT-IR, XRD, SEM, and it is conformed that the guanidine group was introduced into chitosan main chains. After guanidylation, the solubility of chitosan is improved from acidic $\mathrm{pH}$ to neutral. Furthermore, chitosan biguanidine hydrochloride showed better antibacterial activity than chitosan. The antibacterial activity of guanidinylated chitosan enhanced with increasing substitution degrees. All the results imply guanidinylated chitosan will be useful as a potential new antibacterial agent.

Received: April 7, 2009

Accepted: June 3, 2009

Published: October 9, 2009

\section{REFERENCES}

1. A. Ogino, M. Kral, and M. Yamashita, Appl. Surf. Sci., 255, 2347 (2008).

2. D. Gupta and A. Haile, Carbohydr. Polym., 69, 164 (2007)

3. S. Davarpanah, N. M. Mahmoodi, M. Arami, H. Bahrami, and F. Mazaheri, Appl. Surf. Sci., 255, 4171 (2009).

4. E. Pascual and M. R. Julia, J. Biotechnol., 89, 289 (2001).

5. G. A. F. Roberts and F. A. Wood, J. Biotechnol., 89, 297 (2001).

6. Z. Jia, D. Shen, and W. Xu, Carbohydr. Res., 333, 1 (2001).

7. Y. Xie, X. Liu, and Q. Chen, Carbohydr. Polym., 69, 142 (2007).

8. X. F. Liu, Y. L. Guan, D. Z. Yang, Z. Li, and K. D. Yao, J. Appl. Polym. Sci., 79, 1324 (2001).
9. W. Xie, P. Xu, W. Wang, and Q. Liu, Carbohydr. Polym., 50, 35 (2002).

10. D. Trong-Ming, K. Chia-Fong, and C. Wen-Yen, Polym. J., 34, 418 (2002).

11. K. Kurita, H. Ikeda, and M. Shimojoh, Polym. J., 39, 945 (2007).

12. Y.-J. Jeon, P.-J. Park, and S.-K. Kim, Carbohydr. Polym., 44, 71 (2001).

13. L. Mounim, B. Fouad, and C. Nour-Eddine, Corros. Sci., 50, 2914 (2008).

14. L. Y. Qian, Y. Guan, B. H. He, and H. N. Xiao, Polymer., 49, 2471 (2008).

15. M. L. Wallace, AATCC Rev., 11, 18 (2001).

16. Y. F. Pan, H. N. Xiao, G. L. Zhao, and B. H. He, Polym. Bull., 61, 541 (2008).

17. Y. M. Zhang, J. M. Jiang, and Y. M. Chen, Polymer., 40, 6189 (1999).

18. A. Martin, F. Petra, and H. Gertraud, Biomacromolecules, 4, 1811 (2003).

19. T. Seo, Y. Shimomura, and T. Unishi, Kobunshi Ronbunshu, 53, 70 (1996).

20. N. Yoshikawa, J. Jpn. Soc. Powder Powder Metall., 54, 556 (2007).

21. Yoshimura and Yurika, Seni Gakkaishi, 63, 146 (2007).

22. L. Liu, Y. Li, and Y. Fang, Carbohydr. Polym., 60, 351 (2005).

23. G. Huacai, P. Wan, and L. Dengke, Carbohydr. Polym., 66, 372 (2006).

24. H.-C. Ge and D.-K. Luo, Carbohydr. Res., 340, 1351 (2005).

25. V. Singh, D. N. Tripathi, and A. Tiwari, Carbohydr. Polym., 65, 35 (2006).

26. L. Liu, Y. P. Li, Y. Li, and Yue-E. Fang, Carbohydr. Polym., 57, 97 (2004).

27. R. F. Stockel, U. S. Patent 5637681 (1997). 